\title{
Proliferative behaviour and cytogenetic changes in human renal-cell carcinoma
}

\author{
W. de Riese ${ }^{1 *}$, E. Allhoff ${ }^{1}$, M. Werner ${ }^{2}$, J. Atzpodien ${ }^{3}$, H. Kirchner ${ }^{3}$, C. G. Stief ${ }^{1}$, M. Djamilian ${ }^{1}$, \\ R. Schlick' ${ }^{\prime}$, and U. Jonas ${ }^{1}$ \\ 'Department of Urology, ${ }^{2}$ Laboratory of Cytogenetics, Institute of Pathology, and ${ }^{3}$ Department of Hematology and Oncology, \\ Hannover Medical School (HMS), Konstanty-Gutschow-Strasse 8, W-3000 Hannover 61, Federal Republic of Germany
}

Summary. From 1986 until 1990, in vivo proliferation rates (PRs) in 110 patients with renal-cell carcinoma (RCC) were immunohistochemically determined by the Ki-67 assay. It could be demonstrated that the PRs of RCCs range between only $1 \%$ and $15 \%$. Due to its low proliferative kinetics in vivo, tumor cytogenetic investigations of this malignancy remain rare. During short-term in vitro culture, the PRs of this neoplasm increased $(21 \%-82 \%)$. Therefore, 36 untreated human RCCs were cultured in vitro for cytogenetic analysis using the Gbanding technique. In all, $77.8 \%(28 / 36)$ of the renal malignancies investigated exhibited an aberration of chromosome 3 , which seems to serve as a marker for this malignancy. Whereas tumor stage showed no correlation with PR, tumor grade exhibited a strong correlation with this parameter. According to the data presented herein, immunohistochemical determination of the tumor-specific PR using the monoclonal antibody $\mathrm{Ki}-67$ is a practicable, reliable and reproducible method that complements conventional histological tumor grading and staging. This parameter appears to be useful in identifying RCC patients at high risk, especially at early stages that are identical in tumor stage and grade.

For $>100$ years, pathologists and clinicians have been engaged in examining proliferative patterns and behaviour of human malignancies as compared with normal tissue. This is necessary for a better understanding of pathogenesis, therapeutic principles and individual prognosis. Flamming (1882) and Waldeyer (1888) were the first investigators to describe the histomorphological conception of "cell division, mitosis and cell proliferation" in human malignancies [8]. In different malignant tumors, pathologists have found a correlation between the mitosis rate determined in histological specimens and the individual clinical course of patients with neoplasias [10, 18].

* To whom correspondence should be addressed
Mitosis, however, represents only a short phase in the active cell cycle. Microscopically, only $1 \%-5 \%$ of all DNAsynthesizing cells are detectable in histological specimens $[15,17]$; therefore, this can be regarded only as an indirect parameter of the proliferative pattern of the tissue.

It took a long time for the direct detection of tumorspecific proliferation rates (PRs) to become possible. By autoradiographic studies using the thymidine incorporation assay, direct measurement of the portion of DNAsynthesizing cells was achieved for the first time. In 1979 Rabes and co-workers [15] presented a clinical report of PRs in renal-cell carcinoma $(\mathrm{RCC})$ using this technique. These authors found low PRs $(<20 \%)$ and a correlation between PR and recurrence rate in a series of ten RCC patients. The main disadvantages of this method, however, involve (a) the extracorporeal organ perfusion (ex vivo) required after tumor nephrectomy, (b) the exposure of patients to radioactivity and, thus, (c) the lack of practicability of the technique in routine diagnosis.

The successful preparation of monoclonal antibodies represented a relevant advance in this area [12]. In 1983 Gerdes et al. [5] isolated and characterized a human nuclear antigen (termed $\mathrm{Ki}-67$ ) present only in DNA-synthesizing cells; its expression is present in normal as well as in malignant cells but is absent from resting cells [7]. Using frozen sections and immunohistochemical staining techniques as outlined by Gerdes et al. [6] and Cordell et al. [4], individual in vivo PRs in normal and malignant tissue can now be obtained directly.

In recent years an increasing number of chromosomal aberrations have been described in human hematopoietic neoplasms $[13,23]$. This finding emerges from the proliferative behaviour and the high mitotic rates of these malignancies in vivo. Because of the low spontaneous PR in vivo (only up to $15 \%$ ), tumor cytogenetic investigations of human $\mathrm{RCC}$ remain rare [16, 22]. Direct in vivo preparation of malignant renal tissue obtains only a few mitotic cells; furthermore, karyotyping of the cells is impaired by irregular contractions of the chromosomes [1]. In the present study, the technique of in vitro preparation of human RCC is described, which enables the attain- 
ment of higher numbers of proliferative malignant cells and, thus, reproducible chromosomal findings. Furthermore, individual in vivo PRs are correlated with conventional tumor stage and grade as well as with the clinical courses of the corresponding RCC patients.

\section{Patients and methods}

A total of 110 patients with RCC who showed no evidence of metastatic disease at the time of surgery $\left(\mathrm{N}_{0}, \mathrm{M}_{0}\right.$ according to imaging techniques) entered this ongoing study for measurement of individual PRs in vivo. Successful short-term in vitro culture and banding analysis was successful in 36 of 47 cases $(76.6 \%)$. The in vivo/in vitro PRs were compared in all 36 of these instances. Table 1 illustrates tumor staging and grading of the 36 cases of RCC analysed.

Normal and malignant renal tissues were obtained by conventional radical nephrectomy. A macroscopically homogeneous area that was free of fibrosis, necrosis or haemorrhage of the tumor was excised for preparation. Figure 1 exhibits schematically the tumor cell preparation. Samples of excised normal and malignant renal tissue were taken for in vitro cell preparation, and other samples were obtained for histological examination as reference slides ( $H \& E$ staining). Furthermore, samples were stored in fluid nitrogen for frozen sectioning followed by immunohistochemical analysis and measurements of the in vivo PRs as described elsewhere [6].

\section{Preparation of primary cell cultures according to the cell-cluster technique}

After mincing and enzymatic treatment with collagenase, the fragments of fresh tissue were centrifuged and washed twice in RPMI 1640 medium. Subsequently, the tissue clusters were resuspended in a centrifuge tube containing 2-4 ml culture medium (RPMI 1640 supplemented with $15 \%$ foetal calf serum and $1 \%$ penicillin) and vigorously dispersed by means of a Pasteur pipette. The suspension was allowed to sediment for $1 \mathrm{~min}$, and the supernatant containing $>90 \%$ of the single cells with low viability and cell debris was decanted. The pellet, whose content comprised by $>90 \%$ small clusters of approximately $10-15$ cells each, was resuspended and seeded in culture. The cell clusters were incubated at $37^{\circ} \mathrm{C}$ in a humidified atmosphere containing $5 \% \mathrm{CO}_{2}$ in $25-\mathrm{cm}^{2} \mathrm{Fal}-$ con flasks (Biochrom, Berlin, FRG), to each of which $5 \mathrm{ml}$ culture medium had been added. The small cell clusters attached to the flasks within $24 \mathrm{~h}$ and grew to an almost confluent monolayer, in most cases within $7-14$ days of cell culture $[13,17]$.

\section{Chromosome analysis}

Cytogenetic analysis was carried out on days $7-14$ of primary culture, depending on the proliferation of the tumor cells. In all, $0.1-0.2 \mu \mathrm{g} / \mathrm{ml}$

\section{Specimen for reference histology} and frozen sections

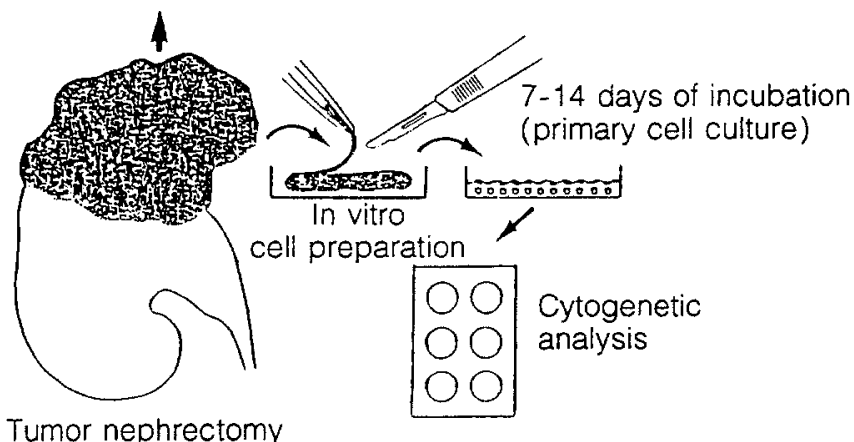

Fig. 1. Schematic representation of tumor-cell preparation for in vitro culturing and cytogenetic analysis
Table 1. Tumor stage and grade of the 36 RCCs investigated for in vivo/in vitro $P R s$ and cultured in vitro for tumor cytogenetic analysis

\section{Patients}

(n)

Stage

pT $1-2$

pT 3

pT 4

9

23

Grade

G 1

G 2

G 3

11

10

15

25

30.6

27.8

41.6

colchicine $(30-60 \mathrm{~min})$ or $0.02 \mu \mathrm{g} / \mathrm{ml}$ colcemid $(2-3 \mathrm{~h})$ was added to the cell cultures. The cells were detached by $0.025 \%$ trypsinethylenediaminetetraacetic acid (EDTA) solution and then treated with $0.075 \mathrm{M}$ potassium chloride solution for $15-30 \mathrm{~min}$. After this hypotonic treatment, the cells were fixed two or three times with cold methanol-acetic acid $(3: 1, v / v)$. Chromosome preparations were obtained using the air-drying technique and the slides were kept at room temperature for $3-5$ days before banding. Karyotype analysis was routinely performed using the (GTG) [20] and (CBG) techniques [21] and, in some cases, the (QFQ) technique [2] for the identification of the $Y$ chromosome. Up to 15 metaphases were karyotyped in each case, with only well-banded metaphases being karyotyped according to the International System for Cytogenetic Nomenclature (ISCN) [11].

\section{Analysis of the constitutional karyotype}

To define the constitutional karyotype of the patients, normal kidney tissues were prepared for in vitro cultures in the same manner described above for tumor samples. Cytogenetic analysis was carried out by the same procedure. When normal renal tissue was not available or normal renal cells did not grow in vitro, phytohaemagglutinin-stimulated peripheral blood lymphocytes were karyotyped.

\section{Preparation of in vivo and in vitro slides for determination of $P R S$}

As outlined above, normal and malignant renal tissues were stored in fluid nitrogen. Frozen sections were prepared for the immunohistochemical Ki-67 assay as described by Gerdes and co-workers [6] so as to obtain the in vivo PR directly. Furthermore, cells of the primary cell culture that had been transferred to cell-culture flasks were directly placed in special in vitro slide chambers (Fig. 2; NUNC Company, Wiesbaden, FRG). On the day during which the chromosomal analysis began, the in vitro slides were also stained for immunocytochemical Ki-67 assay $[6,16]$.

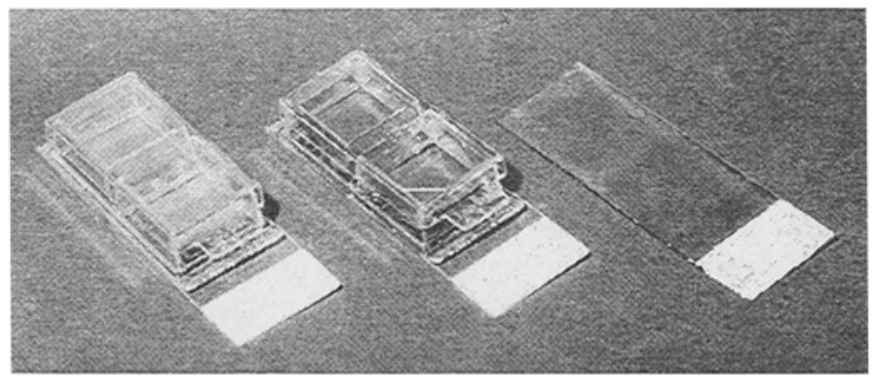

Fig. 2. Slide chamber for in vitro growth of malignant renal cells 

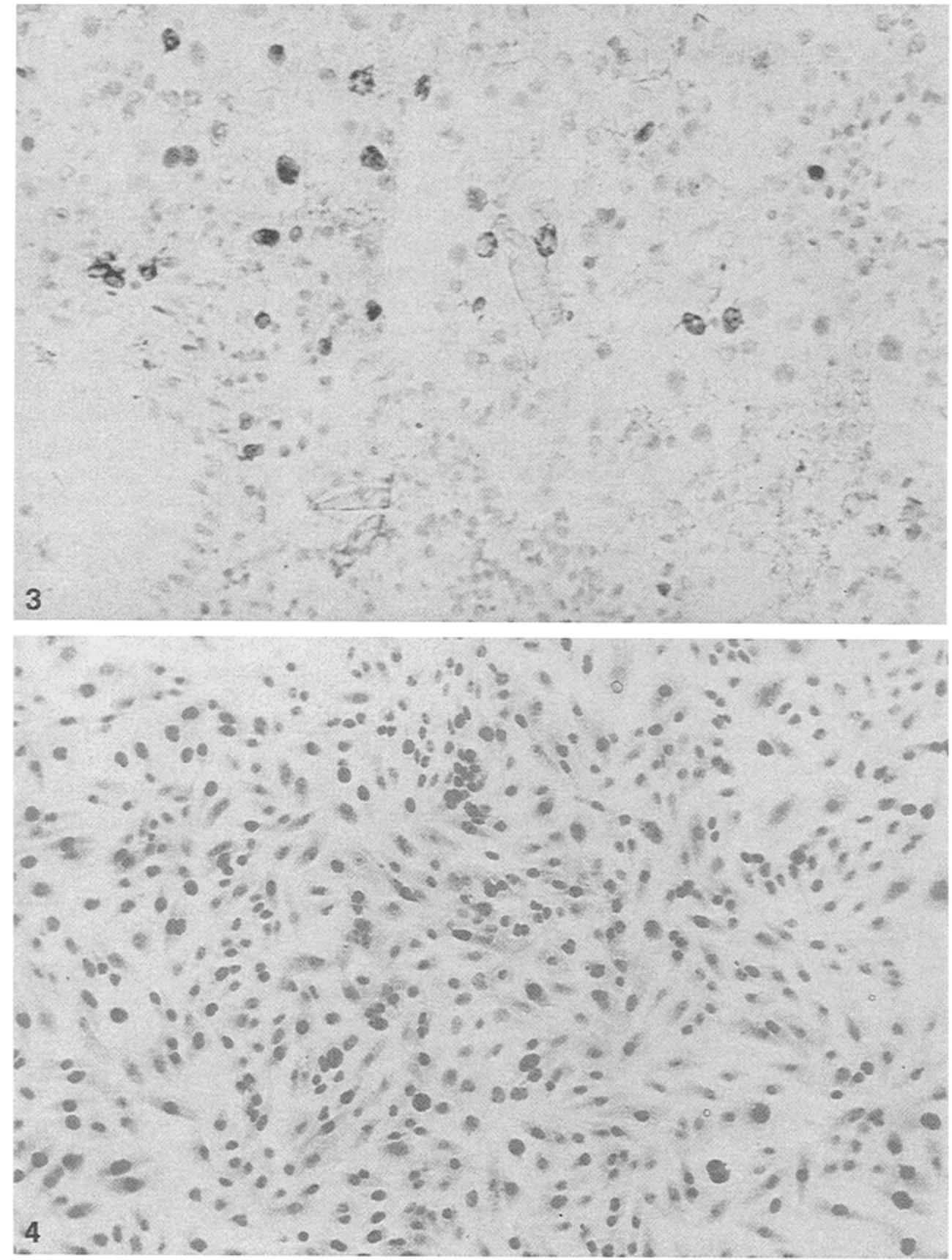

Fig. 3. Immunohistochemical in vivo staining of an undifferentiated RCC using the $\mathrm{Ki}-67$ technique. Positive cells are stained darkly. PR, $15 \%$; original magnification, $\times 120$

Fig. 4. In vitro short-term cell culture of the same RCC illustrated in Fig. 3, showing immunocytochemical staining obtained using mAb Ki-67. PR, $82 \%$; original magnification, $\times 80$

Gerdes and colleagues $[5,7]$ provided the monoclonal antibody $\mathrm{Ki}-67$, which binds to a human nuclear antigen associated with cell proliferation. Cell-cycle analyses demonstrated that this nuclear antigen was detected by $\mathrm{Ki}-67$ only in the $\mathrm{G}_{1}, \mathrm{~S}, \mathrm{G}_{2}$ and $M$ phases of proliferating cells, regardless of viability, but not in $\mathrm{G}_{0}$ cells [7]. Thus, the Ki-67 assay established an easy, fast and reproducible method of determining the growth fractions of tumors in vivo [6] as well as in vitro [16]. The Ki-67 staining method was performed as follows. The acetone- and chloroform-fixed cells were exposed for approximately $30 \mathrm{~min}$ to monoclonal antibody that had been diluted in RPMI 1640 medium. After

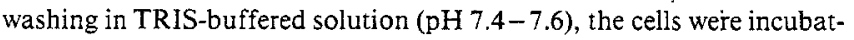
ed with rabbit-anti-mouse IgG and then exposed to APAAP (alkaline phosphatase anti-alkaline phosphatase) complex after another washing [4]. Subsequently, the slides were stained with fast red and counterstained with hemalum $[6,16]$. Presence of the specific antigen was indicated by a red instead of a blue color reaction after counterstaining.

\section{Results}

Table 1 delineates the histological grade and stage of all $36 \mathrm{RCCs}$ assigned to this study. As demonstrated, culturing of not only undifferentiated tumors but also lowgrade RCCs was successful. The success rate for in vitro culture was $87.2 \%(41 / 47)$, but correct banding for tumor cytogenetic analysis succeeded in only 36 cases $(76.6 \%)$. Whereas normal renal tissue showed PRs of around $1 \%$ and well-differentiated RCC tumors exhibited PRs ranging between $1 \%$ and $3 \%$, poorly differentiated tumor tissues showed values of up to $15 \%$ (Fig. 3). Following in vitro culture, PRs of malignant renal tissues in- 


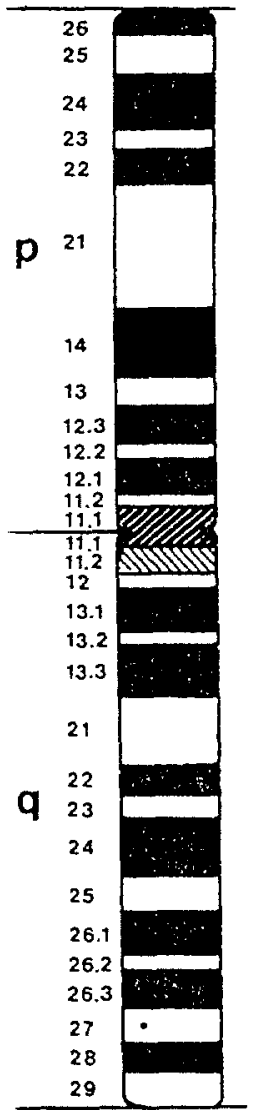

Fig. 5. Schematic representation of a normal chromosome 3 according to the ISCN classification [11] creased considerably, ranging between $21 \%$ and $82 \%$ (Fig. 4).

Figure 5 gives a schematic representation of a normal chromosome 3. Figure 6 illustrates the G-banded karyotype of an in vitro cultured RCC, showing a deletion of the short (p) arm of chromosome 3, which was the chromosome most involved in tumor-induced aberrations. In $28(77.8 \%)$ of the 36 RCCs analysed, various aberrations on chromosome 3 were observed, including deletion of the short arm or translocation of different chromosomal segments to the deletion-altered portion of the chromsome. Six tumors exhibited aberrations on chromosome 3 exclusively, showing no changes in other chromosomes (Fig. 7). In $22.2 \%$ of the cases $(8 / 36)$, aberrations on chromosomes other than chromosome 3 were observed (Fig. 8). Chromosomal aberrations were noted neither in normal kidney cells nor in peripheral blood lymphocytes.

As illustrated in Fig. 9, the shortest possible interval between sampling and storage of the specimens is essential for the correct determination of individual PRs. Rates measured at $3.5 \mathrm{~h}$ after tumor nephrectomy amounted to only approximately $50 \%$ of those initially determined.

The determination of the percentage of Ki-67-positive cells was performed as described by Gerdes et al. [6]. To exclude sampling errors, several samples of solid tumor tissue must be obtained, depending on the individual tumor size (Table 2). The highest PR found for all speci-

3
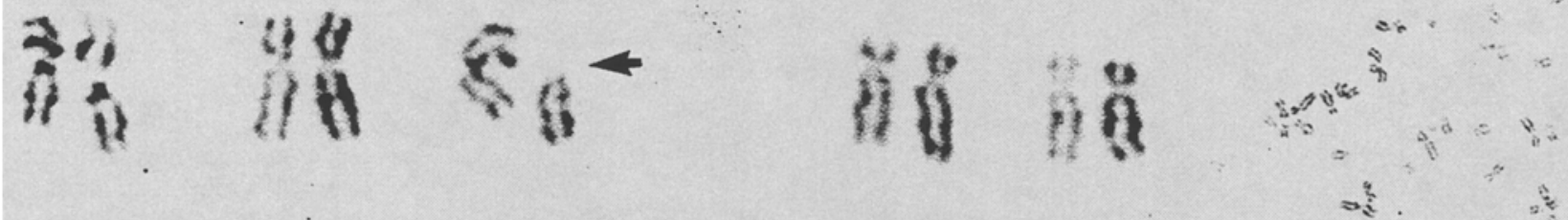

1

2

3

4

5
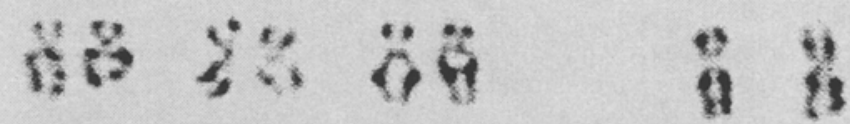

3

ดै

ห̊ii

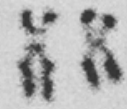

विस

6

7

8

9

10

11

12

$x \quad x$
a)

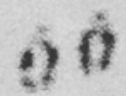
(4)
it is
i⿱艹
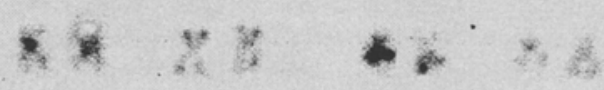
6
14
15
16
17
18
$19 \quad 20$
2122

Fig. 6. G-banded karyotype of an RCC cultured in vitro; note the deletion of both short (p) arms of chromosome 3 (arrow) 
Table 2. Number of specimens according to tumor size for representative measurement of PRs

\begin{tabular}{lll}
\hline Tumor size & Specimens $(n)$ & \\
\cline { 2 - 3 } & Peripheral & Central \\
\hline$<3 \mathrm{~cm}$ & 2 & 1 \\
$3-6 \mathrm{~cm}$ & 4 & 2 \\
$>6 \mathrm{~cm}$ & 6 & 2 \\
\hline
\end{tabular}

Proliferation rates: peripheral $>$ central mens analysed in a given case was considered to be representative of the entire tumor.

From 1986 until 1990, PRs in 110 patients with RCC were immunohistochemically measured using the $\mathrm{Ki}-67$ assay. As determined using histology and imaging techniques, these patients showed no evidence of metastatic spread at the time of tumor nephrectomy. Table 3 gives an overview of the PR, histological tumor staging ( $\mathrm{pT}$ ) and grading $(\mathrm{G})$ of the 110 cases investigated. The classifica-

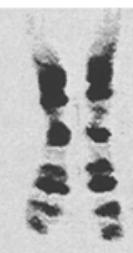

1

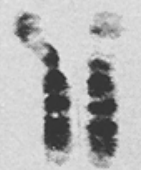

6

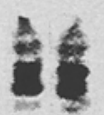

13

719

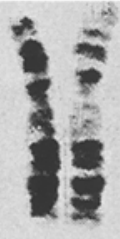

2

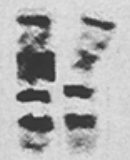

7

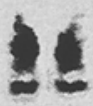

14

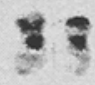

20

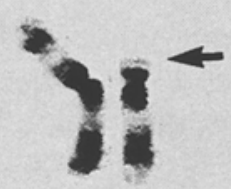

3

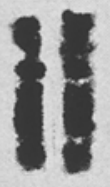

4

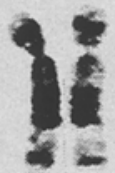

5

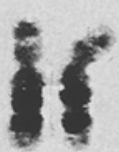

8

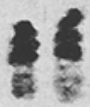

15

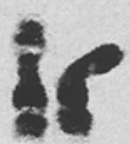

9

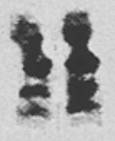

10

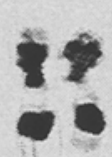

11

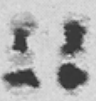

17

7

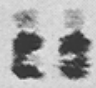

16

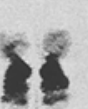

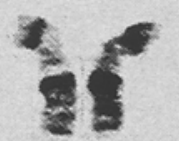

$x x$
Fig. 7. Another case of a karyotyped RCC; deletion of one short (p) arm of chromosome 3 is the only aberration (arrow)

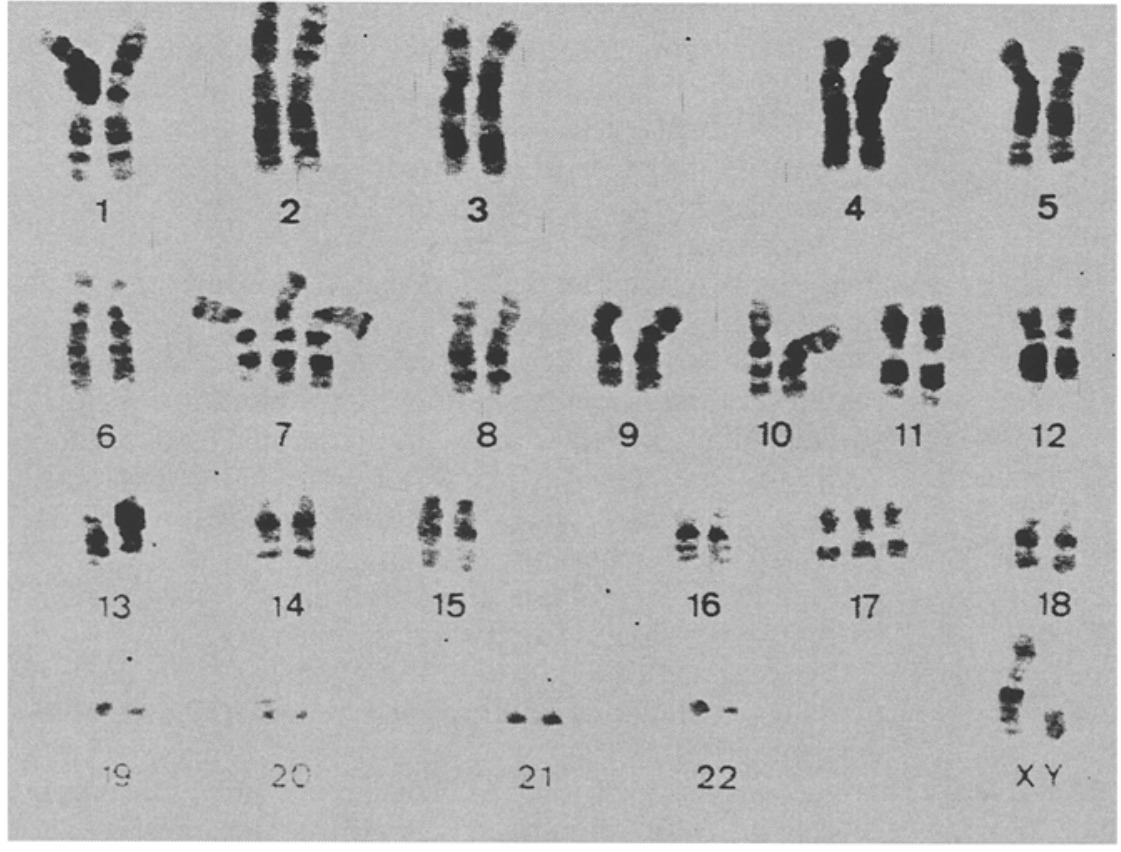

Fig. 8. G-banded karyotype of an RCC cultured in vitro; note the 2 normal chromosomes 3 combined with trisomy of chromosomes 7 and 17 
Table 3. Correlation of tumor stage and grade with PRs

\begin{tabular}{llll}
\hline \multicolumn{4}{c}{ PRs $(n=110)^{\mathrm{a}}$} \\
\cline { 2 - 4 } & $0 \%-4 \%$ & $>4 \%-9 \%$ & $>9 \%$ \\
\hline Stage & & & \\
pT 1 - 2 & 31 & 24 & 16 no \\
pT 3 & 10 & 17 & 12 correlation \\
Grade & & & \\
G 1 & $25(74 \%)$ & 7 & 2 \\
G 2 & 24 & 12 & 14 \\
G 3 & 3 & 8 & $15 / 58 \%)$ \\
\hline
\end{tabular}

a $1986-1990, \mathrm{~T} 1-3, \mathrm{~N}_{0}, \mathrm{M}_{0} ; P<0.001$

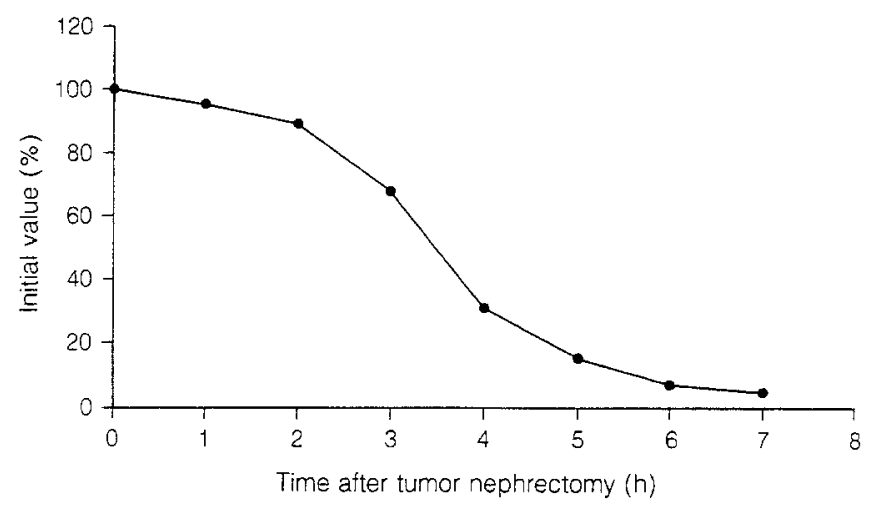

Fig. 9. In vivo PRs plotted against the time of specimen collection (mean values of 10 different RCC tumors)

tion of all RCC tumors was done according to the actual (TNM) system of the IUCC (International Union Against Cancer) [9]. There was no correlation between individual PR and tumor stage (pT; Table 3). In contrast to these findings, a strong correlation between PR and tumor grade was observed (G; Table 3 ). In low-stage tumors (pT1-2), 5-fold variations in PR were measured; we noted large tumors with low PRs and small tumors $(<3 \mathrm{~cm}$ in diameter) with PRs of $>9 \%$.

Thus far, $15(16.3 \%)$ of the 110 patients investigated in the present ongoing study have developed relapsing tumors (mean follow-up, 2.8 years). In all, 11 cases whose tumor recurred during the follow-up period exhibited PRs of $>9 \%$ at the time of tumor nephrectomy; the remaining 4 patients showed PRs ranging between $4 \%$ and $9 \%$. Three patients with low-stage tumors (pT1-2) whose disease recurred showed PRs of $>9 \%$.

\section{Discussion}

RCC occurs spontaneously and is hereditary as well. A reciprocal translocation $3 ; 8$ was reported by Cohen et al. [3] in ten members of a family that was predisposed to RCC. These authors suggested that this chromosomal rearrangement predisposes carriers to develop RCC. Familial RCC is rare; non-familial renal cancer occurs much more frequently. However, reports on the cytogenetic features of this disease are scanty. Yoshida et al. [22] and other authors [1] have reported on several cases of cytogenetic analyses in RCC using short-term in vitro cultures. Although karyotyping was not described in detail in all of the cases, several structural changes in chromosome 3 were observed.

The in vivo PRs in RCC are low, ranging up to only $15 \%$ as determined by the immunohistochemical Ki-67 assay (see Fig. 3). Because of this low proliferative potential, only a few mitotic cells can be obtained by biopsy; furthermore, direct karyotyping of the cells is impaired by irregular contractions of the chromosomes [1,22]. Therefore, reports on the chromosomal features of human $\mathrm{RCC}$ are rare.

Several authors have described different aberrations on chromosome 3 using direct karyotyping of the tumor cells [3, 13]. Yoshida et al. [22] were among the first authors to karyotype malignant renal cells after short-term in vitro culture. Following short-term in vitro culture, the PRs increase, which improves the cytogenetically evaluable output. Malignant renal cells prepared in vitro in the manner outlined above were recently characterized using conventional cytological, cytochemical and immunocytochemical measures [17]. Malignant renal cells were exclusively obtained by the cell-cluster preparation technique.

The aberration on chromosome 3 was the most common cytogenetic finding in the 36 cases of non-familial RCC investigated. None of the patients showed constitutional aberrations on chromosome 3 of their normal cells. Structural changes in chromosome 3 were detected in $77.8 \%(28 / 36)$ of cases; these alterations involved the loss of different segments of the chromosome. It seems that this defect is the initial cytogenetic change and that it triggers genetic instability during the clonal development and progression of human RCC. Other non-random and accidental chromosomal changes represent subsequent events. Our findings thus corroborate the hypothesis that the deletion of a chromosomal segment coding for suppression results in uncontrolled proliferation of normal tubular cells. The duration of this phenomenon accounts for malignant transformation in cases of RCC. These chromosomal aberrations were not observed in normal cells of the RCC patients; therefore, the $3 p$ deletion must be an acquired, specific chromosomal defect in non-familial RCC.

According to the data presented herein, chromosome 3 can be described as the marker chromosome of RCC. Becasue the loss of segments on the short arm of chromosome 3 was not microscopically demonstrable in 8 of the 36 tumors, it seems possible that a mutation or loss of DNA may take place at a submicroscopic level, analogous to that demonstrated for retinoblastoma and Wilms' tumor as previously outlined by Kovacs and coworkers [13]. Further molecular biology studies, however, are required to evaluate the meaning of this specific chromosomal defect for the development of RCC.

As outlined in Fig. 9, fresh tumor tissue must be immediately stored in fluid nitrogen for correct and reliable determination of the tumor-specific PRs. This observation correlates with the in vitro growth rates of tumor cells, which also essentially depend on the interval be- 
tween nephrectomy and tissue sampling [17]. Confirming the data published by Rabes et al. [15], higher PRs were always measured in the peripheral zones of the tumors as compared with the central zones. This is obviously nutrition-related due to the better blood circulation in the peripheral areas. Furthermore, necrosis and cysts initially develop in the central zones of tumors, a phenomenon that is often observed macroscopically.

According to the in vivo PRs obtained in the present study, it can be concluded that in contrast to tumor stage (pT), tumor grade (G) exhibits a strong correlation with the individual PR. The individual tumor stage cannot be concluded from the PR, as tumor stage is a function of cell proliferation as well as of the time of tumor growth, with the latter parameter not being measurable at the time of diagnosis. Some large RCCs exhibited a low PR. These data explain the clinical observation in cases of $\mathrm{RCC}$ in which, despite a non-surgical approach, for various reasons almost a proliferative arrest is noted at longterm follow-up [19]. These in vivo data correspond to the PRs previously found in breast cancer by Lelle et al. [14]: a positive correlation between histological grading, recurrence rate and PRs was observed as well.

In conclusion, immunohistochemical determination of the tumor-specific PR using the monoclonal antibody $\mathrm{Ki}-67$ is a practicable, reliable and reproducible method that complements conventional tumor staging and grading. Measurement of the individual PRs appears to be an additional diagnostic parameter for the detection of RCC patients at high risk, especially at early stages showing identical histological features.

\section{References}

1. Berger CS, Sandberg A, Todd IA (1986) Chromosomes in kidney, ureter, and bladder cancer. Cancer Genet Cytogenet 23:1-24

2. Caspersson T, Zech L, Johannsson C, Modest EJ (1970) Identification of human chromosomes by DNA-binding fluorescent agents. Chromosoma 30:215-227

3. Cohen AJ, Li FP, Berg S, Marchetto DJ, Tsai S, Jacobs SC, Brown RS (1979) Hereditary renal cell carcinoma associated with a chromosomal translocation. N Engl J Med 301.592-595

4. Cordell JL, Falini B, Erber NW, Ghosh AK, Abdulaziz Z, MacDonald S, Pulford KAF, Stein H, Mason DY (1984) Immunoenzymatic labeling of monoclonal antibodies using immune complex. es of alkaline phosphatase and monoclonal antialkaline phosphatase (APAAP complexes). J Histochem Cytochem 32:219-229
5. Gerdes J, Schwab U, Lemke H, Stein H (1983) Production of a mouse monoclonal antibody reactive with a human nuclear antigen associated with cell proliferation. Int J Cancer 31:13-20

6. Gerdes J, Dallenbach F, Lennert $\mathrm{K}$ (1984) Growth fractions in malignant non-Hodgkin's lymphomas (NHL) as determined in situ with the monoclonal antibody Ki-67. Hematol Oncol 2:365-371

7. Gerdes J, Lemke $H$, Baisch $H$, Wacker $H H$, Schwab U, Stein $H$ (1984) Cell cycle analysis of a cell proliferazion-associated human nuclear antigen defined by the monoclonal antibody Ki-67. J Immunol 133:1710-1715

8. Girod C (1986) Die Entwicklung der Kenntnisse von der Zelle. In: Toellner R (ed) lllustrierte Geschichte der Medizin. Rabe, Stuttgart, pp $1884-1893$

9. Hermanek P, Sobin LH (1987) Classification of urological tumors. In: Hermanek P, Sobin LH (eds) TNM classification of malignant tumors, 47th edn. Springer, Berlin Heidelberg New York, pp $137-139$

10. Hermanek P, Sigl A, Chlepas S (1976) Histological grading of renal cell carcinoma. Eur Urol 2:189-191

11. ISCN (1985) An international system of human cyzogenetic nomenclature. Karger, Basel

12. Köhler G, Milstein C (1975) Continuous cultures of fused cells secreting antibodies of a predefined specificity. Nature $256: 495$

13. Kovacs G, Szücs S, Riese W de, Baumgärtel I (1987) Specific chromosome aberration in human renal cell carcinoma. Int $\mathrm{J}$ Cancer 40:171- 178

14. Lelle RJ, Heidenreich W, Stauch G, Gerdes J (1987) The correlation of growth fractions with histologic grading and lymph node status in human mammary carcinoma. Cancer 59:83-88

15. Rabes H, Carl P, Meister P, Rattenhuber U (1979) Analysis of proliferative compartments in renal adenocarcinoma. Cancer 44:799-804

16. Riese W de, Allhoff E, Lenis G, Liedke S, Feretos P, Jonas U (1989) Bestimmung der Proliferationsrate in-vivo sowie in-vitro beim Nierenzellkarzinom mittels des Ki-67-Assays. (In vivo and in vitro determination of the proliferation rates in renal cell carcinoma with the Ki-67-assay) Aktuel Urol 20:79-84

17. Riese W de, Allhoff E, Pohl U, Lenis G, Liedke S, Atay Z, Jonas U, Warnaar SO (1989) Comparison of human normal and malignant renal cells in vivo and in vitro using cytological, cytochemical and immunocytochemical methods. Invest Urol 3:8-16

18. Schiodt $T$ (1966) Breast carcinoma - a histological and prognostic study of 650 followed-up cases. Munksgaard, Copenhagen

19. Schorn A, Marberger M (1984) Long-term survival of untreated bilateral renal cell carcinoma with supradiaphragmatic vena caval thrombus. J Urol 131:108-109

20. Seabright $M$ (1971) A rapid banding technique for human chromosomes. Lancet II:971-972

21. Sumner AT, Evans HJ, Buckland RA (1971) New technqiue distinguishing between human chromosomes. Nature 232:31-32

22. Yoshida MA, Ohyashiki K, Ochi H, Gibas Z, Pontes JE, Prout GR, Sandberg AA (1986) Cytogenetic studies of tumor tissue from patients with nonfamilial renal cell carcinoma. Cancer Res 46:2139-2147

23. Yunis JJ (1983) The chromosomal basis of human neoplasia. Science $221: 227-236$ 